\title{
Assessment of the Effect of Three Agitation Techniques on the Removal Efficacy of Sodium Hypochlorite for the Organic Films
}

\author{
Saifalarab A Mohmmed ${ }^{1}$, Anas F Mahdee ${ }^{2}$
}

\begin{abstract}
Aim: Root canal irrigation is an essential step in the root canal treatment. The aim of this study was to compare the efficacy of three agitation methods [manual-dynamic irrigation gutta-percha (GP), EndoActivator, and passive ultrasonic irrigation (PUI)] for $2.5 \% \mathrm{NaOCl}$ irrigation solution in debriding two organic films (collagen and hydrogel) from simulated root canal walls.

Materials and methods: Twenty-four Endo-Vu blocks were used to create half root canals using Profile instruments. The working length was $0.5 \mathrm{~mm}$ short of the canal end. The canal was enlarged to 30/06. The canals were allocated into two experimental groups ( $n=12)$ : group I (collagen film models), group II (hydrogel layer models). Each group was subdivided into three equal subgroups $(n=4)$ : manual-dynamic irrigation (GP), EndoActivator sonic irrigation, and PUI. Each half canal was then covered with a flat glass slide, before quantifying the collagen or hydrogel film by using the Image-Pro Plus 4.5 and ipWin 4 software. The data were analyzed using the generalized linear mixed model.

Results: The duration of irrigation had a significant influence on surface area coverage with the residual film (hydrogel, collagen). Exposure of the organic film to PUI irrigation was significantly associated with more film removal than GP irrigation $(p=0.0001)$. Exposure of the organic film to EndoActivator irrigation was significantly associated with more film removal than GP irrigation $(p<0.001)$.

Conclusion: The protocol of EndoActivator agitation of the $\mathrm{NaOCl}$ irrigant is more effective in simulant biofilm removal than gutta-percha pumping but less effective than passive ultrasonic agitation.

Clinical significance: The findings from this study make several contributions to enhance our understanding of the use of passive agitation of $\mathrm{NaOCl}$, when compared to sonic and manual agitation as a final irrigation protocol, in the removal of the biofilm from the apical, middle, and coronal thirds of the root canal.
\end{abstract}

Keywords: Agitation, Biofilm, Irrigation, Root canal, Sodium hypochlorite.

World Journal of Dentistry (2019): 10.5005/jp-journals-10015-1676

\section{INTRODUCTION}

Bacteria that normally inhabit the oral cavity theoretically have the capacity to invade the root canal space during and after pulp necrosis. ${ }^{1}$ These bacteria present in infected root canals in the form of bacterial biofilms on the root canal walls. ${ }^{2}$ Root canal treatment involves biofilm removal from the root canal system by instrumentation and irrigation. ${ }^{3}$ The use of the sodium hypochlorite $(\mathrm{NaOCl})$ irrigant has been suggested with multiple in vitro investigations supporting its effectiveness against both planktonic and biofilm. ${ }^{4-6}$ However, complete removal of bacteria from the root canal system was not possible, prompting speculation on a number of possible reasons. First, incomplete penetration of the irrigant. ${ }^{7}$ Second, rapid consumption of $\mathrm{NaOCl}$ active ions by dentine, organic tissue, and biofilm would render the solution inactive. ${ }^{8}$

It has been advocated that the antimicrobial activity of $\mathrm{NaOCl}$ may be improved by increasing its concentration, ${ }^{9}$ temperature, ${ }^{10}$ and duration of exposure. ${ }^{11}$ Nevertheless, unless replenished, the $\mathrm{NaOCl}$ will be swiftly rendered inactive by the organic tissue. ${ }^{8}$

It is well known that irrigant intracanal agitation has been proposed to improve its replenishment and penetration. ${ }^{12}$ Accordingly, the goal of this study was to develop a more rigorous understanding of the effect of film type, number of repeated irrigation, and irrigant agitation [manual-dynamic irrigation, EndoActivator, and passive ultrasonic irrigation (PUI) agitation techniques] on the removal of the organic (collagen and hydrogel) miming biofilm by the $\mathrm{NaOCl}$ irrigant.

\footnotetext{
1,2Department of Conservative Dentistry, College of Dentistry, University of Baghdad, Baghdad, Iraq
}

Corresponding Author: Saifalarab A Mohmmed, Department of Conservative Dentistry, College of Dentistry, University of Baghdad, Baghdad, Iraq, Phone: +964 7906210006, e-mail: Saif.mohmmed.12@ ucl.ac.uk

How to cite this article: Mohmmed SA, Mahdee AF. Assessment of the Effect of Three Agitation Techniques on the Removal Efficacy of Sodium Hypochlorite for the Organic Films. World J Dent 2019;10(6):440-444.

Source of support: Nil

Conflict of interest: None

\section{Materials and Methods}

\section{Construction of Transparent Simple Canal Models}

Endo-Vu blocks (Dentsply Maillefer, Ballaigues, Switzerland) were used to create the canal model tested in this study. First, the blocks ( $n=24)$ were sectioned in a transverse plane just $0.5 \mathrm{~mm}$ below the end of the canal into two halves using a diamond disk (Chiplin and Jacets, Surrey, UK). The halves containing the conical hollow spaces of the simulated canals were discarded. The other intact halves of the blocks were used to create the canal models. A groove of $15.5 \mathrm{~mm}$ length was carved by rotating a size 10 stainless steel file (Flexofile, Dentsply Maillefer, Ballaigues, Switzerland) on 
the flat surface of the block. A half root canal was then created by using Profile instruments (Dentsply, Maillefer, Switzerland) in a crown-down sequence. The working length was $0.5 \mathrm{~mm}$ short of the apical end. The canal was enlarged to an apical size and taper of 30/06, with low-speed rotary handpiece at $300 \mathrm{rpm}$, and 70:1 controlled torque.

\section{Sample Grouping}

Twenty-four canal samples were created and allocated into two experimental groups: group I [collagen film models $(n=12)$ ] and group II [hydrogel layer models $(n=12)$ ]. Each group was subdivided into three equal subgroups [subgroup I for manual-dynamic irrigation gutta-percha (GP) $(n=4)$, subgroup II for EndoActivator sonic irrigation $(n=4)$, and subgroup III for PUI $(n=4)]$.

\section{Application of the Collagen and Hydrogel Films on the Canal Walls}

The collagen film (type I rat tail collagen in $0.6 \%$ acetic acid solution, First Link Ltd, West Midlands, UK) was mixed with calligraphic ink (Kai-Ming, Tainan, Taiwan) in a ratio of 5:1, before painting on the canal surfaces in group I samples by using a brush. ${ }^{13}$ In the same way, the hydrogel layers were mixed with calligraphic ink (5:1) before brushing it on the canal surfaces of group II samples. The hydrogel was created by dissolving $3 \mathrm{~g}$ of gelatin (Merck, Whitehouse Station, $\mathrm{NJ}, \mathrm{USA}$ ) and $0.06 \mathrm{~g}$ of hyaluronan (sodium hyaluronate $95 \%$, Fisher, Waltham, MA, USA) in $45 \mathrm{~mL}$ of distilled water at $50^{\circ} \mathrm{C} \cdot{ }^{14}$ Each model was also demarcated on the end (apical), middle, and opening (coronal) thirds by a scalpel blade (Stanley, Mechelen, Belgium). Each half longitudinal canal was then covered with a flat glass slide. These slides were prepared by sectioning a microscopic slide into three pieces using a diamond disc (Struers Ltd, Solihull, UK). Each piece was used as a glass cover over the canal. The borders of each cover were smoothened by using grinder discs $(250 \mu \mathrm{m}$, Struers Ltd, Solihull, UK). The glass cover was fixed over the canal using cyanoacrylate glue (Loctite, Henkel, UK).

\section{Baseline Quantification of Canal Surface Area Coverage of Collagen Film or Hydrogel Film}

Each model was photographed using a digital camera (Canon, Tokyo, Japan) before applying the irrigation protocol. The camera was mounted onto a copy stand (Kaiser, Buchen, Germany) and the lens directed at the scaled board. Each model was placed onto the board, and its position and alignment were recorded using the horizontal scale. The distance between the camera and the model was recorded using the vertical scale. These records were standardized and used with all subsequent stages of model imaging during the experiments to enable direct comparison. The areas of the canal surface covered with the collagen film or the hydrogel film were quantified by using the Image-Pro Plus 4.5 and ipWin4 software (MediaCybernetics, Silver Spring, USA). These images were set as the baseline for subsequent comparison with the images after irrigation experiments. ${ }^{13}$

\section{Irrigation Experiments}

The manual dynamic irrigation (GP pumping) protocol of subgroup I was adapted from Huang et al. The root canals in each subgroup were irrigated with $2.5 \% \mathrm{NaOCl}$ delivered with a Monoject endodontic 3-mL syringe through a Luer lock 27 gauge Max-IProbeTM needle (Dentsply Maillefer) at a rate of $6 \mathrm{~mL} /$ minute. The irrigating needle was inserted to $4 \mathrm{~mm}$ short of the working length and a total of $27 \mathrm{~mL}$ of solution were delivered. The manual dynamic agitation was carried out through intracanal push-pull manipulation of a tapered gutta-percha point (SybronEndo, Orange, CA, USA) matching the canal dimension and taper (30/06), through the entire working length. One hundred push-pull strokes for 1 minute (each with $5 \mathrm{~mm}$ amplitude) were performed after introducing the first $3 \mathrm{~mL}$ of the irrigant, followed by delivery of the next $6 \mathrm{~mL}$ in two 3-mL boli. Therefore, 100 push-pull strokes were used for each $9 \mathrm{~mL}$ of irrigation. This pattern was repeated four times until the entire $27 \mathrm{~mL}$ is delivered with a total of 300 push-pull strokes.

For the canals in subgroup II, the agitation was carried out by placing the polymer tip of the EndoActivator device (25/04) through the entire working length and agitated for 1 minute with highpower setting. ${ }^{15}$ This was performed after introducing the first $3 \mathrm{~mL}$ of the irrigant, followed by delivery of the next $6 \mathrm{~mL}$ in two 3-mL boli. For the canals in subgroup III, the agitation was carried out by placing stainless steel instrument size 20/02 (IrriSafe; Satelec Acteon, Merignac, France) of the PUI device at the working length (WL); then the agitation was continued for 1 minute. This was performed after introducing the first $3 \mathrm{~mL}$ of the irrigant, followed by delivery of the next $6 \mathrm{~mL}$ in two 3-mL boli. The file was energized by a piezoelectric unit (Suprasson PMax; Satelec Acteon) at power setting 3 and frequency $30 \mathrm{kHz}$ as recommended by the manufacturer. ${ }^{16}$

\section{Image Analysis}

Digital images were taken of each model after irrigation with 9, 18, and $27 \mathrm{~mL}$ of $\mathrm{NaOCl}$ using a digital camera (Canon). All images were taken under standardized model alignment and distance. The digital images were analyzed using the Image-Pro Plus 4.5 and ipWin4 software (MediaCybernetics) to quantify the residual collagen film or the hydrogel film within coronal, middle, and apical levels of the canal.

\section{Data Analysis}

The data representing the areas of canal surface coverage with the collagen film and the hydrogel film at baseline and at different time intervals were entered onto an SPSS database, version 21 (IBM, New York, USA) for statistical analysis. The mean and standard deviation of the percentage of the root canal surface covered with the organic layer after irrigation were performed first. The influence of the potential independent factors (film type, the coronalapical level of the root canal, number of repeated irrigations, and irrigant agitation) on the mean area of canal surface coverage was investigated using the generalized linear mixed model.

\section{Results}

Interesting observations were made that a large amount of stained organic film was flushed out from the root canal during the first stage of irrigation $(9 \mathrm{~mL}, 2.5 \% \mathrm{NaOCl})$ than the remaining stages of irrigation ( $18 \mathrm{~mL}, 27 \mathrm{~mL}$ and $36 \mathrm{~mL}$ ).

An important observation was made (Figs 1 and 2) that the ranking of both film removal was the same in relation to the irrigant activation. However, there was a proportional difference in the extent of removal of each film by each agitation technique. Both collagen and hydrogel films behaved the same toward manualdynamic irrigation (GP) but behaved slightly differently to the EndoActivator, while they behaved very differently to PUI. Thus, the collagen film was less sensitive to activation than the hydrogel film.

The results (Table 1) showed that the mean percentages of the root canal surface covered with the collagen or hydrogel film decreased with the increase in number of stages of irrigation of the 


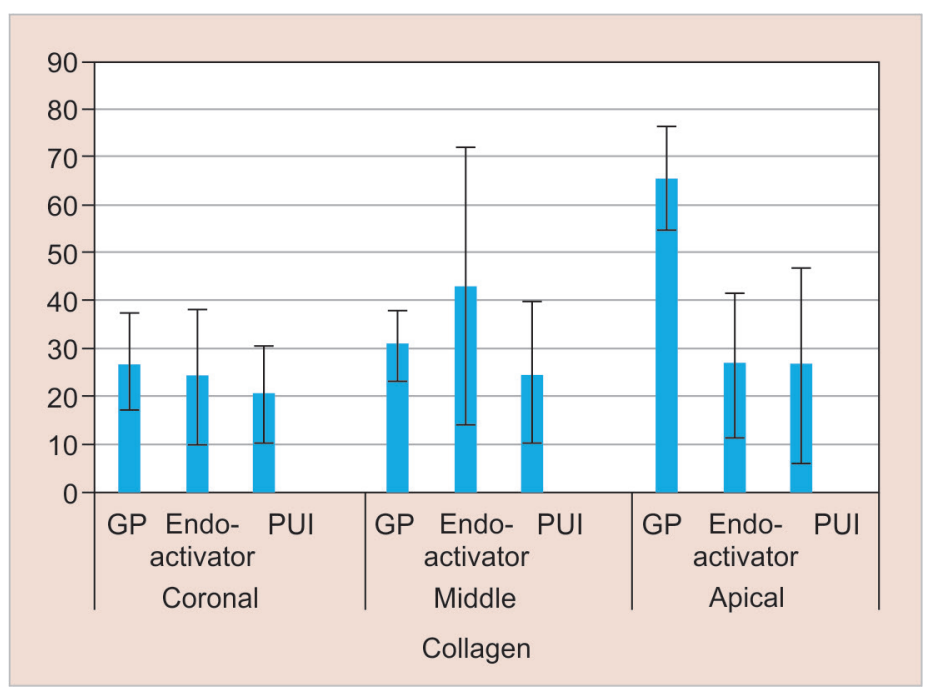

Fig. 1: Mean area percentages of canal coverage with the collagen film after irrigation using GP, Endoactivator, and passive ultrasonic irrigation agitation techniques

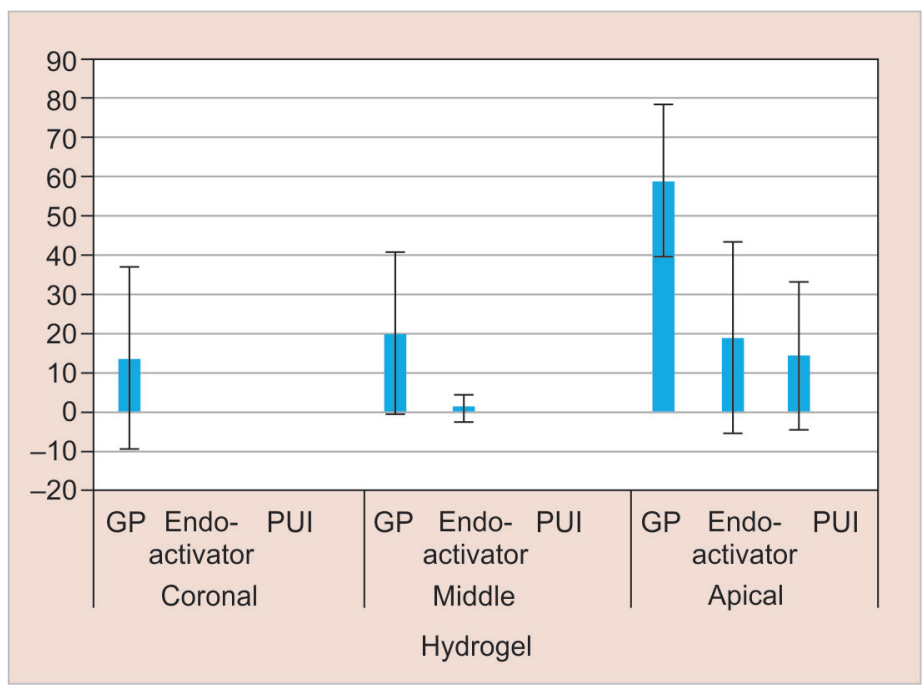

Fig. 2: Mean area percentages of canal coverage with the hydrogel film after irrigation using GP, Endoactivator, and passive ultrasonic irrigation agitation techniques

root canal surface. The mean percentages of the root canal surface covered with the collagen or hydrogel film were the lowest in the coronal third, followed by middle and apical thirds.

The results of generalized linear mixed model analyses for each potential influencing factor using "percentage of the root canal surface covered with the residual collagen or hydrogel film" as the dependent variable are presented in Table 2.

The statistical analysis showed that the mean area covered with the residual collagen film was not significantly $8.3 \%$ more than that of the hydrogel film after irrigation $(p=0.243)$.

Interestingly, the coronal third was $5.7 \%$ and $20.9 \%$ less covered with the residual film than the middle and apical thirds, respectively. These were statistically significant.

The efficacy of irrigation was increased as the area of canal coverage with the residual film was reduced with the number of repeated irrigation. This was statistically significant.

The exposure of the organic film to PUI irrigation was significantly associated with increased film removal when compared to the film exposed to GP irrigation ( $p=0.0001)$. The exposure of the organic film to EndoActivator irrigation was significantly associated with more film removal when compared to the film exposed to GP irrigation $(p=0.0001)$.

\section{Discussion}

The issue of complete removal of the bacterial biofilm from the root canal system has received considerable critical attention. ${ }^{5}$ The present study was designed to assess the effect of different irrigant agitation methods on the ability of the $2.5 \% \mathrm{NaOCl}$ irrigant to remove and destroy the simulant biofilm from a simulated root canal model. The experiments were successful in testing the aim. The artificial infection models were successful to investigate the effect of agitation on the $\mathrm{NaOCl}$ efficacy in removal of organic films from the root canal surface. The subjective observation of this study showed that the four variables, film type, coronal-apical level of the root canal, number of repeated irrigations, and method 
Table 1: Mean area percentages of canal surface coverage with the collagen or hydrogel film after irrigation using GP, Endoactivator, and passive ultrasonic irrigation (PUI) agitation techniques

\begin{tabular}{|c|c|c|c|c|c|}
\hline Matrix & Level of root & Type of agitation & Mean & $n$ & $\begin{array}{l}\text { Std. } \\
\text { deviation }\end{array}$ \\
\hline \multirow[t]{12}{*}{ Collagen } & Coronal & GP & 27.00 & 12 & 9.63 \\
\hline & & EndoActivator & 24.25 & 12 & 13.98 \\
\hline & & PUI & 20.83 & 12 & 9.98 \\
\hline & & Total & 24.03 & 36 & 11.33 \\
\hline & Middle & GP & 30.83 & 12 & 7.30 \\
\hline & & EndoActivator & 43.58 & 12 & 28.90 \\
\hline & & PUI & 25.17 & 12 & 15.09 \\
\hline & & Total & 33.19 & 36 & 20.29 \\
\hline & Apical & GP & 66.04 & 12 & 10.54 \\
\hline & & EndoActivator & 26.58 & 12 & 14.99 \\
\hline & & PUI & 26.42 & 12 & 20.44 \\
\hline & & Total & 39.68 & 36 & 24.38 \\
\hline \multirow[t]{12}{*}{ Hydrogel } & Coronal & GP & 41.29 & 12 & 19.96 \\
\hline & & EndoActivator & 31.47 & 12 & 21.70 \\
\hline & & PUI & 24.14 & 12 & 15.49 \\
\hline & & Total & 32.30 & 36 & 20.32 \\
\hline & Middle & GP & 13.68 & 12 & 23.20 \\
\hline & & EndoActivator & 0.01 & 12 & 0.02 \\
\hline & & PUI & 0.00 & 12 & 0.00 \\
\hline & & Total & 4.56 & 36 & 14.56 \\
\hline & Apical & GP & 19.77 & 12 & 20.45 \\
\hline & & EndoActivator & 0.86 & 12 & 2.88 \\
\hline & & PUI & 0.01 & 12 & 0.01 \\
\hline & & Total & 6.88 & 36 & 14.8 \\
\hline
\end{tabular}

of irrigant agitation, had significant influence on the efficacy of irrigation.

Numerous experimental models have been suggested to examine the efficacy of different irrigation regimens. ${ }^{4}$ The test model used in the present study was chosen to attempt replication of the removal of the clinically relevant biofilm. However, growing biofilms within root canal systems ex vivo is limited by the lack of standardization as well as variation. ${ }^{17}$ For these, two simulant biofilms (collagen or hydrogel) have been used. In addition, the relevant films have been used in previous studies as test models to mimic bacterial biofilms to investigate the outcomes of their reaction with irrigation solution within the root canal system. ${ }^{13,18}$ The black calligraphic ink was used to provide good contrast against the canal walls. Also, it is insoluble in water once dry. ${ }^{13}$

The Image-Pro Plus software was used to quantify the residual film on the root canal wall. This software has been suggested in previous studies for image analysis. ${ }^{13,19}$ The method of quantifying the organic films from the root canal wall showed marked results. However, one limitation associated with this method was single assessor who performed the measurements, which may increase the possibility of bias. For this, a technique was agreed using a standard method for outlining the root canal walls and for setting the threshold of the organic film stain to be quantified. The principal observer and another assessor who was experienced in using the Image-Pro Plus software measured $20 \%$ of the images and this was repeated until sufficient interobserver agreement was achieved. Another attempt to avoid bias was
Table 2: Generalized linear regression analysis for each potential independent variable using area percentage of canal surface coverage as the dependent variable

\begin{tabular}{|c|c|c|c|c|}
\hline \multirow{2}{*}{$\begin{array}{l}\text { Independent } \\
\text { variables (reference } \\
\text { category) }\end{array}$} & \multirow[b]{2}{*}{ Coefficient } & \multicolumn{2}{|c|}{$\begin{array}{c}95 \% \text { confidence } \\
\text { interval }\end{array}$} & \multirow[b]{2}{*}{$p$ value } \\
\hline & & Lower & Upper & \\
\hline $\begin{array}{l}\text { Hydrogel vs } \\
\text { collagen film } \\
\text { (collagen) }\end{array}$ & -18.262 & -48.988 & -12.465 & 0.243 \\
\hline $\begin{array}{l}\text { Middle third } \\
\text { (coronal third) }\end{array}$ & 5.742 & 0.694 & 10.791 & 0.026 \\
\hline $\begin{array}{l}\text { Apical third } \\
\text { (coronal third) }\end{array}$ & 20.884 & 15.836 & 25.932 & 0.0001 \\
\hline $\begin{array}{l}27 \mathrm{~mL} \text { irrigation } \\
\text { (9 mL baseline) }\end{array}$ & -22.925 & -27.973 & -17.876 & 0.0001 \\
\hline $\begin{array}{l}18 \mathrm{~mL} \text { irrigation } \\
\text { (9 mL baseline) }\end{array}$ & -11.836 & -16.884 & -6.788 & 0.0001 \\
\hline $\begin{array}{l}\text { PUl agitation } \\
\text { (GP pumping) }\end{array}$ & -21.660 & -26.708 & -16.612 & 0.0001 \\
\hline $\begin{array}{l}\text { EndoActivator } \\
\text { agitation } \\
\text { (GP pumping) }\end{array}$ & -17.073 & -22.121 & -12.025 & 0.0001 \\
\hline
\end{tabular}

achieved by investigation of the intraobserver reliability. This was achieved by assessing 20 replicate measurements of the organic film in each experimental group and comparing the results taken. The comparison illustrated good agreement between the measurements. This semiautomatic protocol allowed operatorindependent quantitative measurements.

The canal of the root canal model used in the present study was enlarged to an apical size and taper of 30/06 as it has been reported that this apical size and taper is the minimum to deliver the irrigant apically. ${ }^{20}$

The biofilm simulant (collagen, hydrogel) showed relatively similar trends of removal. Nevertheless, the removal rate did differ to some extent since the hydrogel film exhibited a greater removal rate than the collagen film. This may be related to the fact that organic films were not grown on but applied to the surface of the root canal models. More specifically, this can be ascribed to a reliance on physicochemical interactions between the model surface and the film layer alone. The residual collagen film was more than the hydrogel film. This may be related to the fact that the hydrogel is less stable and more hydrophilic than collagen; ${ }^{21}$ consequently, its dissolution by $\mathrm{NaOCl}$ was more than collagen.

After irrigation, the root surface of the coronal level had the significantly $(p<0.05)$ less residual collagen or hydrogel film followed by the middle and apical levels. The possible reason was that the removed debris from the coronal level by the activated irrigant may have impeded the apical movement and flushing action of the irrigant. ${ }^{18}$ However, a $2.5 \% \mathrm{NaOCl}$ irrigant and a $9 \mathrm{~mL}$, 1-minute agitation were insufficient to remove $100 \%$ of the biofilm simulant (collagen, hydrogel). The finding is consistent with findings of past studies that suggested the incomplete removal of the bacterial biofilm after the delivery of the $\mathrm{NaOCl}$ irrigant into the root canal system. 15,19

Although EndoActivator irrigation was significantly more effective than gutta-percha pumping irrigation, it was significantly less effective than passive ultrasonic irrigation. The difference between GP pumping and EndoActivator may be attributed to the fact that manual push-pull motion of the gutta-percha point 
generates frequency less efficient than the automated methods. ${ }^{22}$ The difference between EndoActivator and PUI may be attributed to that the driving frequency of the ultrasonic device is higher than that of the sonic device. A higher frequency results in a higher flow velocity of the $\mathrm{NaOCl}$ irrigant. ${ }^{23}$ This may be the result of more film removal by PUI than EndoActivator irrigation.

The findings of the present study provide information about the outcomes of interaction between the $2.5 \% \mathrm{NaOCl}$ irrigant and the biofilm simulant using the different irrigation protocols. This may support the importance of intracanal irrigation with optimal removal efficacy to improve the prognosis of the root canal treatment. Further research is essential for the understanding of antibacterial efficacy of the bacterial biofilm by different agitation and concentrations of $\mathrm{NaOCl}$ within the root canal system.

A number of possible future studies using the same experimental set up are apparent. It would be interesting to assess the effects of other variables such as canal curvature and apical size on the efficacy of agitation of $\mathrm{NaOCl}$.

\section{Conclusion}

Within the limitations of the current study design, the transparent simple canal models allowed quantification and comparison of the efficacy of removal of two biomolecular films (hydrogel, collagen). The protocol of EndoActivator agitation of the $2.5 \% \mathrm{NaOCl}$ irrigant is more effective in simulant biofilm removal than gutta-percha pumping agitation of the $\mathrm{NaOCl}$ irrigant but less effective than passive ultrasonic agitation of $2.5 \% \mathrm{NaOCl}$.

\section{ACKnOWLedgments}

The authors acknowledge that this study is based on the ideas and concepts originated, developed, and under investigation by Professor Kishor Gulabivala, strands of which have been presented at conferences and as master's dissertations.

\section{References}

1. Sundqvist G. Taxonomy, ecology, and pathogenicity of the root canal flora. Oral Surg Oral Med Oral Pathol 1994;78(4):522-530. DOI: 10.1016/0030-4220(94)90047-7.

2. Ramachandran Nair PN. Light and electron microscopic studies of root canal flora and periapical lesions. J Endod 1987;13(1):29-39. DOI: 10.1016/S0099-2399(87)80089-4.

3. European Society of Endodontology. Quality guidelines for endodontic treatment: consensus report of the European Society of Endodontology. Int Endod J 2006;39(12):921-930. DOI: 10.1111/j.13652591.2006.01180.x.

4. Spratt $D$, Pratten J, Wilson $M$, et al. An in vitro evaluation of the antimicrobial efficacy of irrigants on biofilms of root canal isolates. Int Endod J 2001;34(4):300-307. DOI: 10.1046/j.1365-2591.2001.00392.x.

5. Clegg M, Vertucci F, Walker C, et al. The effect of exposure to irrigant solutions on apical dentin biofilms in vitro. J Endod 2006;32(5): 434-437. DOI: 10.1016/j.joen.2005.07.002.

6. Bryce G, O'Donnell D, Ready D, et al. Contemporary root canal irrigants are able to disrupt and eradicate single-and dual-species biofilms. J Endod 2009;35(9):1243-1248. DOI: 10.1016/j.joen.2009.05.034.
7. Bronnec F, Bouillaguet S, Machtou P. Ex vivo assessment of irrigant penetration and renewal during the final irrigation regimen. Int Endod J 2010;43(8):663-672. DOI: 10.1111/j.1365-2591.2010.01723.x.

8. Moorer W, Wesselink P. Factors promoting the tissue dissolving capability of sodium hypochlorite. Int Endod J 1982;15(4):187-196. DOI: 10.1111/j.1365-2591.1982.tb01277.x.

9. De Macedo RG. Optimizing the chemical aspect of root canal irrigation, 1st ed., Enschede: Academic Center for Dentistry Amsterdam; 2013.

10. Cunningham WT, Martin H, Forrest WR. Evaluation of root canal debridement by the endosonic ultrasonic synergistic system. Oral Surg Oral Med Oral Pathol 1982;53(4):401-404. DOI: 10.1016/00304220(82)90442-X.

11. Bukiet F, Soler T, Guivarch M, et al. Factors affecting the viscosity of sodium hypochlorite and their effect on irrigant flow. Int Endod J 2013;46(10):954-961. DOI: 10.1111/iej.12086.

12. Basrani B, Haapasalo M. Update on endodontic irrigating solutions. Endod Topics 2012;27(1):74-102. DOI: 10.1111/etp.12031.

13. Huang TY, Gulabivala K, Ng YL. A bio-molecular film ex vivo model to evaluate the influence of canal dimensions and irrigation variables on the efficacy of irrigation. Int Endod J 2008;41(1):60-71. DOI: 10.1111/j.1365-2591.2007.01317.x.

14. Popa EG, Gomes ME, Reis RL. Cell delivery systems using alginatecarrageenan hydrogel beads and fibers for regenerative medicine applications. Biomacromolecules 2011;12(11):3952-3961. DOI: 10.1021/ bm200965x.

15. Jiang LM, Verhaagen $B$, Versluis $M$, et al. Evaluation of a sonic device designed to activate irrigant in the root canal. J Endod 2010;36(1): 143-146. DOI: 10.1016/j.joen.2009.06.009.

16. Lee SJ, Wu MK, Wesselink P. The efficacy of ultrasonic irrigation to remove artificially placed dentine debris from different-sized simulated plastic root canals. Int Endod J 2004;37(9):607-612. DOI: 10.1111/j.1365-2591.2004.00857.x.

17. Gulabivala K, Stock CJR, Lewsey JD, et al. Effectiveness of electrochemically activated water as an irrigant in an infected tooth model. Int Endod J 2004;37(9):624-631. DOI: 10.1111/j.13652591.2004.00867.x.

18. Verhaagen B, Boutsioukis C, Van der Sluis L, et al. Acoustic streaming induced by an ultrasonically oscillating endodontic file. J Acoust Soc Am 2014;135(4):1717-1730. DOI: 10.1121/1.4868397.

19. McGill S, Gulabivala K, Mordan N, et al. The efficacy of dynamic irrigation using a commercially available system (RinsEndo ${ }^{\oplus}$ ) determined by removal of a collagen 'bio-molecular film' from an ex vivo model. Int Endod J 2008;41(7):602-608. DOI: 10.1111/j.13652591.2008.01408.x.

20. Khademi A, Yazdizadeh M, Feizianfard M. Determination of the minimum instrumentation size for penetration of irrigants to the apical third of root canal systems. J Endod 2006;32(5):417-420. DOI: 10.1016/j.joen.2005.11.008.

21. Otake K, Inomata H, Konno M, et al. A new model for the thermally induced volume phase transition of gels. J Chem Phys 1989;91(2):1345-1350. DOI: 10.1063/1.457157.

22. Mohmmed S, Vianna ME, Penny MR, et al. A novel experimental approach to investigate the effect of different agitation methods using sodium hypochlorite as an irrigant on the rate of bacterial biofilm removal from the wall of a simulated root canal model. Dent Mater 2016;32(10):1289-1300. DOI: 10.1016/j.dental.2016.07.013.

23. Ahmad M, Pitt Ford T, Crum L, et al. Ultrasonic debridement of root canals: acoustic cavitation and its relevance. J Endod 1988;14(10): 486-493. DOI: 10.1016/S0099-2399(88)80105-5. 